\title{
Assessment of eco-security in the Knowledge Grid e-science environment
}

\author{
Xiaoqing Shi *, Jingzhu Zhao, Ouyang Zhiyun \\ Key Laboratory of Systems Ecology, Research Center for Eco-environmental Sciences, Chinese Academy of Sciences, Beijing 100085, China
}

Received 3 March 2005; received in revised form 19 April 2005; accepted 19 April 2005

Available online 2 June 2005

\begin{abstract}
Ecological security is an important basis of the entire human security system, the cornerstone for human survival. Knowing the status of ecological security is crucial for making decisions to avoid ecological disaster. Existing research, both the basic research on ecological security mechanism and information service systems, is still primitive in their abilities to resolve eco-security problems. This paper investigates the eco-security impact factors and identifies eco-security types. Taking urban eco-security as an example, we develop an assessment method including the indicator system and assessment model, and construct an integrated assessment framework based on data integrity, security assessment and security management with the support of the Knowledge Grid e-science environment. The proposed assessment framework enables decision makers to better know the status of eco-security in making policies for achieving sustainability.
\end{abstract}

(c) 2005 Elsevier Inc. All rights reserved.

Keywords: Eco-security; Assessment; Eco-environment; E-science; Knowledge Grid

\section{Introduction}

Since industry revolution, human had begun to suffer from many kinds of pollution and ecosystem degradation, such as air pollution, water pollution, soil loss and degradation, desertification, forest decrease, greenhouse effect, destruction of ozone layer, species diversity decrease. Many eco-environmental problems have caused some severe security problems. Human survive have faced serious threat.

Many politician and scientists have concerned ecological security problems. In 1977, Lester R. Brown

\footnotetext{
The research work was supported by Key Project of KIP, CAS (KZCX3-SW-424, KZCX3-SW-423), National Natural Science Foundation of China (No. 70373066), and the National Basic Research and Development Program (973 project no.2003CB317001).

* Corresponding author. Tel.: +86 10 62849805; fax: +86 10 62849188.

E-mail address: shixq@mail.rcees.ac.cn (X. Shi).
}

(the former president of the Worldwatch Institute) discussed the problems of the threat to human coming from ecosystem breakdown. The environmental security problem is often neglected because ecosystem degradation is a long time process (Brown, 1977). In 1987, environmental security as a formal science term is appeared in the famous report named "Our Common Future". Environmental degradation is fundamentally implicated in economic and political insecurities (Myers, 1993). Entering the 21th century, severe ecological degradation has been widely concerned. Human realized that environment security is not only the environmental problems but also the ecological degradation problems. In the Johannesburg Summit 2002 Conference on the World Summit on Sustainable Development, all the participated countries have a common concern on ecological security problems.

Some nations and international organizations have also began to support some researches on the eco-security problems, some research reports have released, such 
as, NATO's (North Atlantic Treaty Organization) "Environment \& Security in an International Context, 1999"; German's "Environment and Security: Crisis Prevention Through Cooperation, 2000"; America's "Environmental Change \& Security Project Report, 2000"; and, Canada's "Environment, Scarcity and Violence, 1999".

America has paid more attention to the eco-security problem. In 1993, America Defensive Ministry established the office of environmental security. Since 1995, the office began to deliver reports about environmental security problems to president each year.

Since ninety centuries, China has begun to pay attention to the ecological security problems. According to the state's fifteenth five-years plan, one of the main tasks of government is to emphasize ecological structure and control ecosystem degradation. For achieving this aim, the core of the ecological structure focuses on establishing state eco-security system (SESS).

Eco-security is the key part of the state-security and society stability. In China, the basic structure of an ecological security system is the ecological net, which includes the following four layers:

(1) The large ecological unit and topographic unit.

(2) The ecological corridors and natural defense within the first layer, as well as the linkage node of ecological net.

(3) The area where human live.

(4) The ecological vulnerable area.

The current research areas of eco-security problems include: state eco-security, agriculture ecological security, land utility and ecological security, nature protection area and ecological security, water security, resource security, and eco-security system (Gleick, 1994; Holst, 1989; Homer-Dixon et al., 1993; Mische, 1998; Rosegrant and Ringler, 1997; Soffer, 2000; Swaminathan, 2001). Due to its complexity, existing research on eco-security are limited in their ability to resolve eco-security problems, even the concept is still confused. As ecological security assessment needs a large and real-time data support and it also needs to feed back its result to the policy maker on time, so it requires the support from the system that could provide information instantly and truly. E-science Knowledge Grid meets this requirement.

This paper focuses on the assessment of eco-security. Firstly, we discuss the concept of ecological security. Secondly, the main eco-security factors are analyzed, and the eco-security types are identified. Thirdly, taking urban eco-security as an example, an assessment method including the indicator system and assessment model is developed. Fourthly, we address the assessment in Knowledge Grid e-science environment, and than construct integrated assessment framework based on data integrity, security assessment and security management in the Knowledge Grid e-science environment.

\section{Ecological security}

\subsection{Eco-security problems}

The development of human society have exploited natural ecosystems such as land, forest, and water, and caused changes in component, structure and function of natural ecosystem. As the serious results, landscape is fragmented, natural species are reduced, some of them are extinct, some exotic organisms and even useless materials (waste) are introduced, air and water is polluted, and soil is eroded. These changes have brought out many serious eco-environmental problems: population growth; soil erosion and degradation; forest decrease; air pollution; water pollution; poverty; disaster; greenhouse gases; ozone layer depletion; energy shortage; ocean pollution; and, species extinction. Furthermore, these serious eco-environmental problems have caused many even more serious ecological security problems: environmental health problems, ecological refugee, and resource war, species extinction. These severe eco-security problems have menaced the vital interests of a nation or people seriously, and blocked the development of human society further. It is urgent to find effective ways to resolve the problems.

\subsection{Definition of eco-security}

In 1989, IIASA (International Institute for Application System Analysis) gives two kinds of definition (Xiao and Chen, 2002). One is broad definition-ecological security is the status reflecting the threat to human living, health, basic right, living guarantee, necessary resources, social orders and the abilities to adapt to environmental change, it includes nature, economy and society eco-security. Another is a narrow definitionthe security of nature and semi-nature ecosystem, that is, the reflection of the ecosystem integrity and health. In our eco-environmental protection outline, ecological security is defined as the status that national economy, social development, and the necessary eco-environment for people living is less or no threatened. Eco-security emphasizes that the environmental and ecological conditions that support the ecosystems are sufficient.

\section{Assessment approach}

\subsection{General assessment principles}

Generally, the assessment of a system should consider two important effective factors: scale and time. Scale decides the assessment area; different areas have different 
assessing principles. Time decides the assessment period; different times have different assessing principles. Furthermore, scale and time are decided by the characteristics of assessment objects (Shi, 2002).

An ecosystem has the following characteristics: integrity, dynamic feature, limited capacity and resources. So, the assessment of eco-security should consider the following principles.

Principle 1. Integrity principle. An ecological system is a continuous natural ecological unit and has the integrated ecological function. So choosing assessment area should consider the integrity.

Principle 2. Dynamic principle. Functions of ecosystem are supported by all kinds of dynamic material flows and energy flows. The functions vary with time, so the factor of dynamic change should be taken into account in assessment (Zhuge and Shi, 2000).

Principle 3. Limitation principle. Ecosystem capacity and resources have certain limitation. Eco-environment cannot recover if disaster exceeds some limitation. And, as soon as the eco-environment problems appear, even if the damage degree is within the limitation, human still has to made great effort to recover them.

\subsection{Eco-security type}

Eco-security includes biological security, environmental security and ecosystem security, which correspond to three parts of an ecological environment: organism, environment and ecosystem. The organism security mainly involves in biological diversity, species protection and species invasion. The environment security involves in water, air, soil, noise, and plant. The ecosystem security involves in ecosystem structure, function and development. Fig. 1 depicts an eco-security tree.

\subsection{A case study: Urban eco-security}

\subsubsection{Indicator system of urban eco-security}

According to the ecology principle, a city can be regarded as an urban ecosystem that consists of human

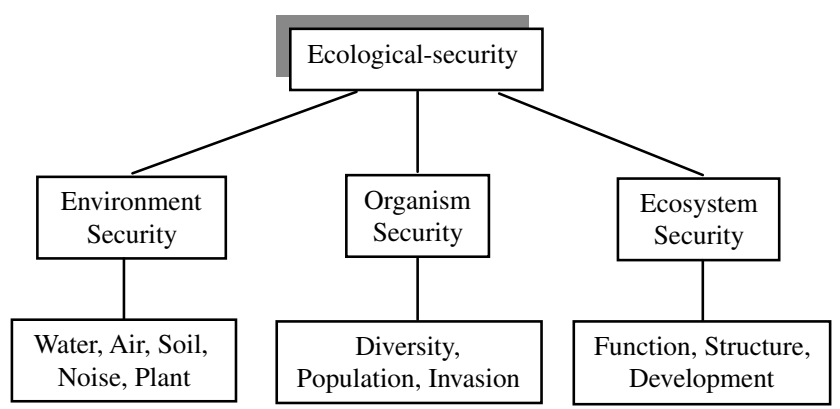

Fig. 1. Eco-security tree. and the environment around them. Sound environment and sufficient resources are the basic condition to urban development. Losing the support of ecological and environmental condition will cause urban ecological security problems. Urban eco-security is described as a kind of urban development status, with which the ecological and environmental conditions keep supporting urban development and human living sufficiently.

The quantitative analysis for knowing urban ecosecurity status requires a set of indicator systems reflecting the eco-security level. According to above discussion, urban ecological security includes two aspects of security: resources security and environmental security. Resource security includes water resource security, land resource security and productive resource security. Productive resources mainly include the resources that main industry and inhabitant living needs in a city. The industries mainly include the industry with higher profit and the industry that is very necessary for living. For the environmental security, the content includes nature environment, such as water quality security, air quality security, noise security, disaster control security, and manmade environment such as greening. For measurement, we choose water shortage index for water resource security, urban structure land per person for land resources security; resource load for resource security; environmental pollution index for environmental security. Therefore, we can get the indicator system framework of the urban eco-security as given in Table 1.

\subsubsection{Assessment model}

3.3.2.1. Expected value. Security is a relative concept. It can be described as a guarantee degree of an expected value. Generally, the expected value depends on the acceptable degree. In urban eco-security assessment, the expected value depends on the acceptable degree of eco-environment conditions that support the development of urban ecosystems. According to above discussion, urban eco-security includes resource security and environmental security. Resource security depends on urban development level and local resource richness. Environmental security depends on the acceptable degree of city inhabitant. As expected values have no unified standard, therefore, there are different methods for the determination of expected values. For the resource security, the expected values are often determined by resource supply. For environmental security, the expected values are often determined by state standard. Furthermore, as acceptable degree varies in different time and region, the expected value is changeable according to different needs.

3.3.2.2. Index calculating model. For comparison, each original data should be disposed by the following method. Let $X_{i}(i=1,2,3, \ldots, n)$ be the original value, $O_{i}\left(m_{i}\right.$ is the indicator signal, $i=1,2,3, \ldots, n)$ is the un-security 
Table 1

Eco-security indicator system

\begin{tabular}{|c|c|c|c|c|}
\hline Object $(U)$ & Principle $1(V)$ & Principle $2(Q)$ & Indicators $\left(m_{i}\right)$ & Expected value $(S)$ \\
\hline \multirow{10}{*}{ Urban ecological security } & Resource Security & Water resource & Water shortage index & Guarantee Value/State \\
\hline & & Land resource & Urban structure land per person & Standard \\
\hline & & Product resource & Ecological load & \\
\hline & & Living resource & Ecological load & \\
\hline & Environment Security & Nature environment & Water quality security index & \\
\hline & & & Air quality security index & \\
\hline & & & Noise security index & \\
\hline & & & Solid waste security index & \\
\hline & & & Sand frequency & \\
\hline & & Artificial environment & Green area per person & \\
\hline
\end{tabular}

index of indicator $m_{i}, 0 \leqslant O_{i} \leqslant 1, S_{i}$ is the expected value discussed above at time $t$.

For some indicators, the bigger the value is, the more security it reflects. For some other indicators, the bigger the value is, the less security it reflects. Therefore, the model takes the following two forms.

For the former case,

$O_{i}\left(m_{i}\right)=\left\{\begin{array}{lll}0, & \text { if } X_{i} \geqslant S_{i} & \text { (a) } \\ 1-X_{i} / S_{i}, & \text { if } X_{i}<S_{i}\end{array}\right.$

For the latter case,

$O_{i}\left(m_{i}\right)=\left\{\begin{array}{lll}0, & \text { if } X_{i} \leqslant S_{i} & \text { (a) } \\ 1-S_{i} / X_{i}, & \text { if } X_{i}>S_{i} & \text { (b) }\end{array}\right.$

Let $U$ be the total eco-security value, $w$ be the weight that can be got by using the method of AHP. For any layer security, the total un-security value can be measured in terms of the following function:

$U=\sum_{i=1}^{n} w_{o i} \cdot \mathrm{O}_{i}\left(m_{i}\right)$

\subsubsection{Security assessment grades}

As the security and non-security are relative, the boundary between them is vague. We use fuzzy mathematical method for classifying the grades (Verbruggen and Zimmermenu, 1999). The four fuzzy grades are: L (little un-security), F (fairly un-security), V (very unsecurity), and $\mathrm{E}$ (extreme un-security). The corresponding possibility functions are constructed and shown in Fig. 2. The possibility functions of the integrated assessment value indicate the overall extent of the eco-security

$$
\begin{gathered}
\mu_{\mathrm{E}}(u)= \begin{cases}0 & 0 \leqslant u \leqslant 0.8 \\
\frac{u-0.8}{0.1} & 0.8<u \leqslant 0.9 \\
1 & 0.9<u \leqslant 1\end{cases} \\
\mu_{\mathrm{V}}(u)= \begin{cases}0 & 0 \leqslant u \leqslant 0.6 \\
\frac{u-0.6}{0.1} & 0.6<u \leqslant 0.7 \\
1 & 0.7<u \leqslant 0.8 \\
\frac{0.9-u}{0.1} & 0.8<u \leqslant 0.9 \\
0 & 0.9<u \leqslant 1\end{cases}
\end{gathered}
$$

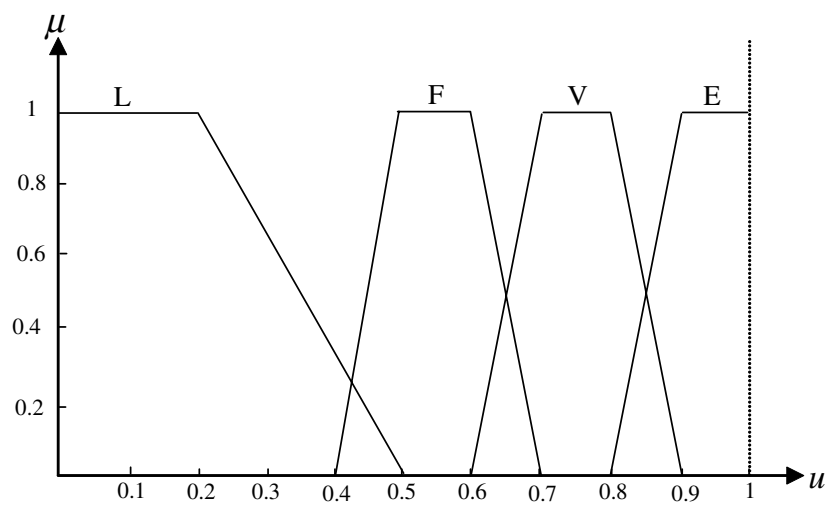

Fig. 2. Possibility function.

$\mu_{\mathrm{F}}(u)= \begin{cases}0 & 0 \leqslant u \leqslant 0.4 \\ \frac{u-0.4}{0.1} & 0.4<u \leqslant 0.5 \\ 1 & 0.5<u \leqslant 0.6 \\ \frac{0.7-u}{0.1} & 0.6<u \leqslant 0.7 \\ 0 & 0.7<u \leqslant 1\end{cases}$

$\mu_{\mathrm{L}}(u)= \begin{cases}1 & 0 \leqslant u \leqslant 0.2 \\ \frac{0.5-u}{0.3} & 0.2<u \leqslant 0.5 \\ 0 & 0.5<u \leqslant 1\end{cases}$

where $u$ is the un-security index value $\mathrm{O}\left(m_{i}\right)$ or $U$. $\mu$ is the possibility degree.

\subsubsection{Assessment series}

According to above discussion, we get the un-security index of each indicator and the synthesis unsecurity index. The index value can be calculated to be the possibility by using the possibility function discussed in Section 3.3.3, where $U=\left\{\mu_{\mathrm{L}}, \mu_{\mathrm{F}}, \mu_{\mathrm{V}}, \mu_{\mathrm{E}}\right\}$, $\mathrm{O}\left(m_{i}\right)=\left\{\mu_{i \mathrm{~L}}, \mu_{i \mathrm{~F}}, \mu_{i \mathrm{v}}, \mu_{i \mathrm{E}}\right\}, \quad(i=1,2, \ldots, n)$. Let axis $x$ be the index value and axis $y$ be the possibility, then the assessment series could be constructed as shown in Fig. 3. The series is divided by four areas: 'A and G1', 'B, G1 and G2', and 'C, G2, and G3', and 'D and G3'. The security grade of any assessment result can be determined after judging by the assessment 


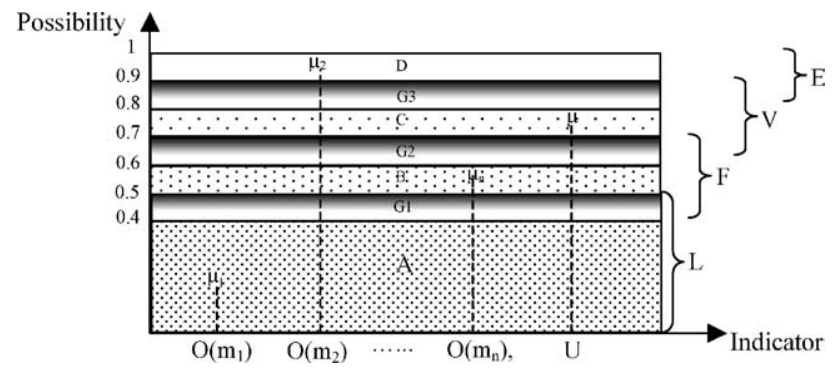

Fig. 3. Assessment series.

series. For example, let $\mathrm{O}\left(m_{1}\right)=\mu_{1}, \mu_{1}$ falls in area $\mathrm{A}$, and then the corresponding grade is L. Let $\mathrm{O}\left(m_{2}\right)=$ $\mu_{2}, \mu_{2}$ falls in area $\mathrm{D}$, and then the corresponding grade is E. Let $\mathrm{O}\left(m_{n}\right)=\mu_{n}, \mu_{n}$ falls in area $\mathrm{B}$, and then the corresponding grade is $\mathrm{F}$. Let $U=\mu, \mu$ falls in area $\mathrm{C}$, and then the corresponding grade is $\mathrm{V}$. If $\mu_{x}$ falls in the gray area, the eco-security grade is judged by the size of the possibility degree. Therefore, decision makers can know the security level of each affected aspect and the whole city. Furthermore, the un-security aspects affecting urban development are available. It is very helpful for decision makers to make relevant strategies for urban eco-security.

\subsubsection{Assessment in the Knowledge Grid e-Science environment}

The Knowledge Grid is defined as an intelligent and sustainable Internet application environment that enables people or virtual roles (mechanisms that facilitate interoperation among users, applications, and resources) to effectively capture, publish, share and manage explicit knowledge resources. It also provides on-demand services to support innovation, cooperative teamwork, problem solving, and decision-making. It incorporates epistemology and ontology to reflect human cognition characteristics; exploits social, ecological and economic principles; and adopts techniques and standards developed during work toward the next-generation Web (Zhuge, 2004a). The China Knowledge Grid Research Group leads research in this area (http://kg.ict.ac.cn). The Knowledge Grid forum is an informal academic community for research and application in this area (http://www.knowledgegrid.net). Research across the Knowledge Grid and ecology will form important contribution to both areas.

Fig. 4 shows the architecture of the e-Science Knowledge Grid environment for Eco-Lab. The development and operation of the Eco-Lab require the cooperation of the ecologists, the IT professionals, and the policy and decision makers. The environment monitoring sensor network is the mediation of the nature environment and the Internet/Intranet. The Knowledge Grid provides the assessment of eco-security the following distinguished characteristics of information services.

\begin{tabular}{|c|c|}
\hline Ecologists & Decision Makers \\
\hline IT Professionals & Eco-Lab \\
\hline \multicolumn{2}{|c|}{ Knowledge Grid } \\
\hline \multicolumn{2}{|c|}{ Internet / Intranet } \\
\hline \multicolumn{2}{|c|}{ Environment Monitoring Sensor Network } \\
\hline \multicolumn{2}{|c|}{ Natural Environment: Ecological Net } \\
\hline
\end{tabular}

Fig. 4. Architecture of e-Science Knowledge Grid environment for Eco-Lab.

(1) Integrity and effectiveness of information services. The normal organization theory of the Knowledge Grid enables resources of different types to be organized according to semantic normal forms (Zhuge, 2004c), so that resources can be accurately and effectively retrieved and managed.

(2) Single Semantic Image data services (Zhuge, 2004b; Zhuge, 2005a). The intelligent clustering function of the Knowledge Grid can actively cluster the most relevant information and then synthesized them to provide data in single semantic image for assessing and decision-making.

(3) Semantic data expression, understanding and sharing. The semantic interconnection function of the Knowledge Grid enables users and applications to express and publish semantic rich information, and the information distributed in different areas can be properly used based on understanding.

(4) Mediated the Eco-Lab and the environment monitoring sensor network and the Internet/Intranet. Through the sensor network, the whole e-science environment becomes a harmonious humannature-machine environment.

Currently, we are developing an Eco-Lab for assessing urban eco-security as a part of e-science based on the proposed framework. The development carries out with the cooperation of technical flow, knowledge flow and service flow in the evolving, self-organizing, selfmanaging, and scalable Knowledge Grid environment suggested in (Zhuge, 2005b).

\section{Assessment framework}

According to the discussion above, eco-security assessment framework includes the following process:

(1) Determine assessment area for urban eco-security. In the light of urban eco-security principles and the characteristics of research objects, choose the scope of research object. 


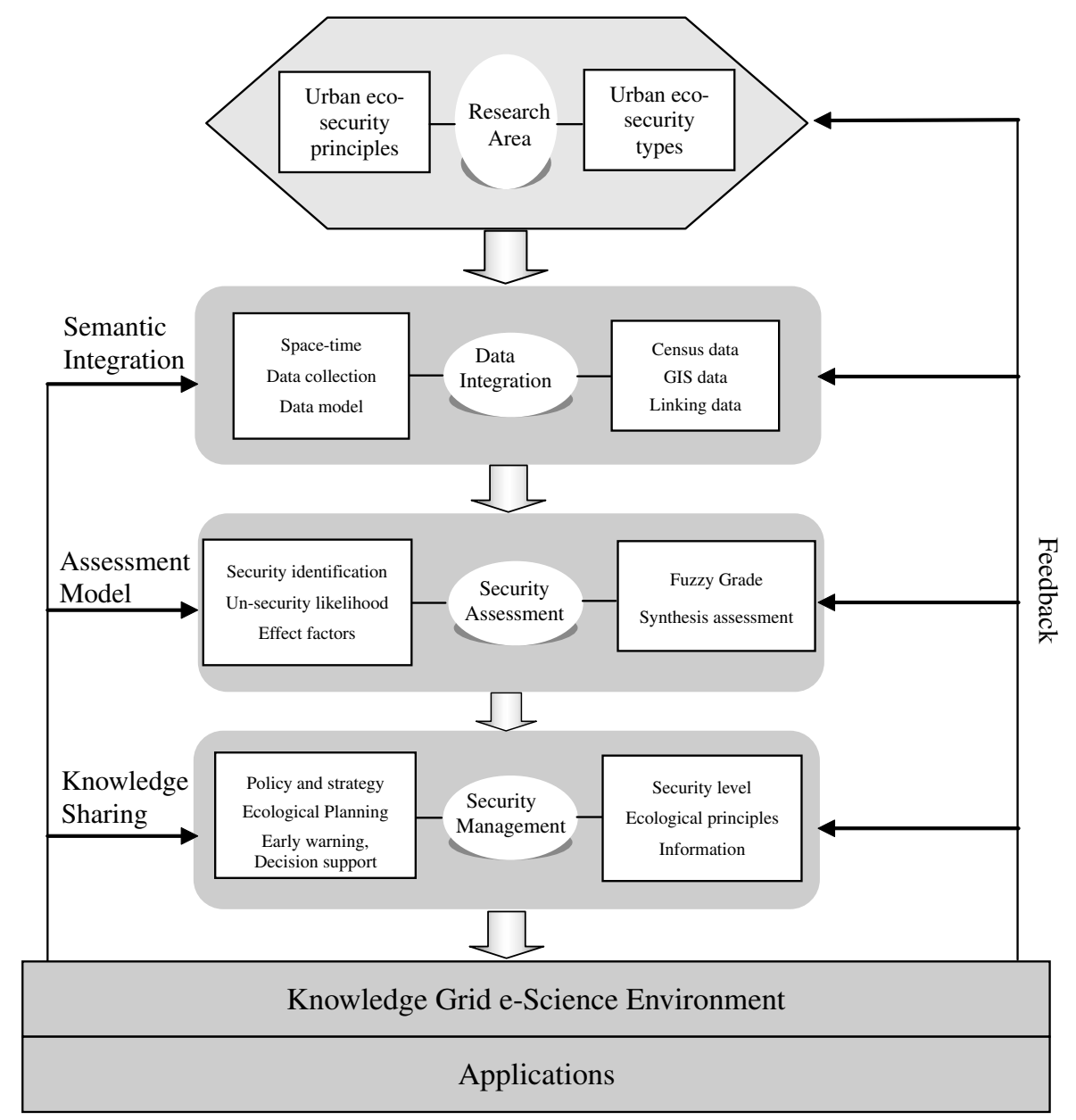

Fig. 5. Urban eco-security assessment in Knowledge Grid e-Science environment.

(2) Propose the indicator system. According to the assessment content and eco-security type, establish the indicator system of eco-security, collect original data such as census data and GIS data, and then establish data model for indicator measurement.

(3) Develop assessment method, make assessment criteria, and choose expected value. As there exists no exact watershed between security and un-security at a time point, the border between them is not very sharp. Fuzzy grades are used in the assessment.

(4) Establish a feedback system. It is necessary to take into account the dynamic characteristics of the research object. A feedback system is constructed between eco-security management and the assessment process. Relevant work on dynamic environment has been reported (Shi, 2002; Zhuge and Shi, 2003).

(5) The Knowledge Grid e-science environment supports data acquisition, effective sharing, and intelligent processing for the assessment.
As shown in Fig. 5, the Knowledge Grid e-science environment supports the assessment process in the following three aspects:

(1) Semantic integration of different types of data collected from various data source such as GIS, databases and the Web.

(2) Assessment models developed by scientists of different countries and stored in different sites.

(3) Knowledge and experience sharing in ecological planning, early warning, policy making and decision making.

\section{Conclusion}

Eco-security, the main constraint of development, is becoming more and more important with the rapid development of our modern society and information technology. Knowing the status of eco-security is crucial for making sustainable development policy. Based on the notion of eco-security especially urban eco-security, 
this paper proposes an assessment approach and suggests an integrated assessment framework. The Knowledge Grid e-science environment supports data integrity, security assessment and security management. The assessment method is flexible and practical by using assessment series and a feedback system. With the support of the Knowledge Grid environment (Zhuge, 2004a), the proposed method provides a vehicle for decision makers to know whether the influence of development is secure for both human and nature environment, so that they can adjust strategies on time to achieve the sustainable development.

Ongoing work is to implement the Eco-Lab based on the Knowledge Grid, to apply this research result to study the urban eco-security issue of Beijing, and to apply the proposed approach to the assessment of the security of the future interconnection environment (Zhuge, 2005b).

\section{References}

Brown, L.R., 1977. An untraditional view of national security. World Watch 14, 21-22.

Gleick, P.H., 1994. Water, war and peace in the middle east. Environment 36 (3), 6-15.

Holst, J.J., 1989. Security and the environment: a preliminary explanation. Bulletin of Peace Proposals 20 (2), 123-128.

Homer-Dixon, T., Boutwell, H.J., Rathjens, W.G., 1993. Environmental change and violent conflict. Scientific American 39, 38-43.

Mische, P.M., 1998. Global Issues Series: Ecological Security \& the UN System: Past, Present, Future. Global Education Associations, New York.

Myers, N., 1993. Ultimate Security: The Environmental Basis of Political Stability. W.W. Norton \& Co., New York.

Rosegrant, M.W., Ringler, C., 1997. World food markets into the 21st century: environmental resource constrains and policies. Australian Journal of Agricultural and Resource Economics 41 (03), 401428.

Shi, X.Q., 2002. Dynamic analysis and assessment for sustainable development. Environmental Sciences 14 (1), 88-94.
Soffer, A., 2000. Environmental quality and national security. Water Science and Technology 42 (1-2), 361-366.

Swaminathan, W.S., 2001. Ecology and equity: key determinants of sustainable water security. Water Science and Technology 43 (04), $35-44$.

Verbruggen, H.B., Zimmermenu, H.J., 1999. Fuzzy Algorithms for Control. Kluwer Academic Publishers, Boston.

Xiao, D.N., Chen, W.B., 2002. On the basic concepts and content of ecological security. Chinese Journal of Applied Ecology 13 (31), 348-354.

Zhuge, H., 2004a. China's e-science Knowledge Grid environment. IEEE Intelligent Systems 19 (1), 13-17.

Zhuge, H., 2004b. Semantics, resource and grid. Future Generation Computer Systems 20 (1), 1-5.

Zhuge, H., 2004c. The Knowledge Grid. World Scientific.

Zhuge, H., 2005a. Semantic grid: scientific issues, infrastructure, and methodology. Communications of the ACM 48 (4), 117-119.

Zhuge, H., 2005b. The future interconnection environment. IEEE Computer 38 (4), 27-33.

Zhuge, H., Shi, X.Q., 2000. A dynamic evaluation approach for virtual decision training. IEEE Transactions on Systems, Man and Cybernetics 30 (3), 374-380.

Zhuge, H., Shi, X.Q., 2003. Fighting epidemics in information and knowledge age. IEEE Computer 36 (10), 114-116.

Xiaoqing Shi is an associate professor at the Key Lab of Systems Ecology, Research Center of Eco-environmental Sciences, Chinese Academy of Sciences. Her research interests are ecosystem management, eco-security, dynamic evaluation, and across-disciplinary research. She has published over ten papers in international conferences and journals such as Communications of the ACM, IEEE Computer, and IEEE Transactions on Systems, Man and Cybernetics, Journal of Environmental Sciences, and Journal of Systems and Software.

Jingzhu Zhao is the professor and director of Research Center of Ecoenvironmental Sciences, Chinese Academy of Sciences. His research interests are sustainable development, systems ecology, and ecoeconomy. He has published many papers and books in these fields.

Zhiyun Ouyang is the professor and director of the Key Lab of Systems Ecology, Research Center of Eco-environmental Sciences, Chinese Academy of Sciences. His research interests are ecosystem services, ecosystem management, ecological planning. He has published many papers and books in these fields. 